Int. J. Electrochem. Sci., 16 (2021) Article ID: 210221

International Journal of

ELECTROCHEMICAL

SCIENCE

www.electrochemsci.org

\title{
A Simple Approach to Fabricate a Screen-Printed Electrode and Its Application for Uric Acid Detection
}

\author{
Wulan Tri Wahyuni ${ }^{1,2 *}$, Budi Riza Putra ${ }^{3}$, Rudi Heryanto ${ }^{1,2}$, Eti Rohaeti ${ }^{1}$, Dede Heri Yuli Yanto ${ }^{4}$, \\ Achmad Fauzi ${ }^{1}$ \\ ${ }^{1}$ Analytical Chemistry Division, Department of Chemistry, Faculty of Mathematics and Natural \\ Sciences, IPB University, Indonesia \\ ${ }^{2}$ Tropical Biopharmaca Research Center, Institute of Research and Community Empowerment, IPB \\ University, Indonesia \\ ${ }^{3}$ Department of Chemistry, Faculty of Mathematics and Natural Sciences, Indonesia Defense \\ University, Indonesia \\ ${ }^{4}$ Research Center for Biomaterials, Indonesian Institute of Science, Indonesia \\ *E-mail: wulantriws@apps.ipb.ac.id
}

doi: $10.20964 / 2021.02 .36$

Received: 10 October 2020 / Accepted: 3 December 2020 / Published: 31 December 2020

In this work, we present the development of a simple technique for the easy fabrication of a homemade screen-printed carbon electrode (SPCE) and its analytical application for uric acid detection. The homemade SPCE was fabricated using the painting technique on a polyvinyl chloride (PVC) paper substrate. The conductive ink for the homemade SPCE fabrication was prepared from a combination of graphite to polystyrene (at a 10:2 w/w ratio) for the working and counter electrodes, while the reference electrode consisted of silver and polystyrene (at a 10:2 w/w ratio). The field-emission scanning electron microscope image of the homemade SPCE shows that it has a rough surface, with the flake-like graphite perfectly covering the substrate of the PVC paper. The homemade SPCE provides a signal higher than the commercially available SPCE for electrochemical characterization using $\mathrm{K}_{3} \mathrm{Fe}(\mathrm{CN})_{6}$ and a uric acid solution. The application of the homemade SPCE for uric acid measurements exhibited a detection limit of $1.94 \mu \mathrm{M}$ and a quantitation limit of $6.46 \mu \mathrm{M}$, with an excellent reproducibility (\% relative standard

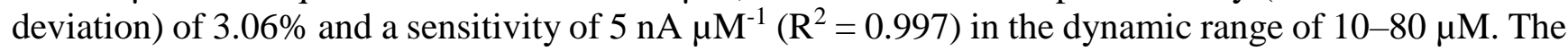
performance of the homemade SPCE also showed good selectivity using ascorbic acid as an interference when its concentration was one-tenth that of uric acid and was evaluated using the amperometry technique. The uric acid in human urine was detected successfully using the homemade SPCE by the standard addition technique, indicating that the SPCE fabricated showed a potency that could be further developed for the electrochemical sensor.

Keyword: Electrode, fabrication, graphite, sensor, uric acid 


\section{FULL TEXT}

(C) 2021 The Authors. Published by ESG (www.electrochemsci.org). This article is an open access article distributed under the terms and conditions of the Creative Commons Attribution license (http://creativecommons.org/licenses/by/4.0/). 